Studer, R.K.; Danuser, B.; Wild, P.; Hildebrandt, H.; Gomez, P. Psychophysiological activation during preparation, performance, and recovery in high- and low-anxious music students. Applied Psychophysiology and Biofeedback, 39(1):45-57, 2014.

\begin{tabular}{|l|l|}
\hline Postprint version & Final draft post-refereeing \\
\hline Journal website & $\underline{\text { http://link.springer.com/journal/10484 }}$ \\
\hline Pubmed link & $\underline{\text { http://www.ncbi.nlm.nih.gov/pubmed/24477850 }}$ \\
\hline DOI & $\underline{10.1007 / \text { s10484-014-9240-2 }}$ \\
\hline
\end{tabular}




\title{
Psychophysiological Activation during Preparation, Performance, and Recovery in High- and Low-Anxious Music Students
}

Authors: Regina Katharina Studer, $\mathrm{PhD}^{1}$; Brigitta Danuser, $\mathrm{MD}^{1}$; Pascal Wild, $\mathrm{PhD}^{1,2}$; Horst Hildebrandt, $\mathrm{MD}^{3}$; Patrick Gomez, $\mathrm{PhD}^{1}$

${ }^{1}$ Institut universitaire romand de Santé au Travail (Institute for Work and Health), University of Lausanne \& University of Geneva, Rte de la Corniche 2, 1066 Epalinges - Lausanne, Switzerland

${ }^{2}$ Institut national de recherche et de sécurité (INRS), Nancy, France

${ }^{3}$ Swiss University Centre for Music Physiology, Zurich University of the Arts, Switzerland

\section{Corresponding author:}

Regina Studer, Rte de la Corniche 2, CH - 1066 Epalinges - Lausanne, Switzerland Phone : 0041 (0) 213147478 / Fax : 0041 (0) 213147478

Mail : regina.studer@hospvd.ch

\begin{abstract}
Purpose and Method: The present study provides a comprehensive view of (a) the time dynamics of the psychophysiological responding in performing music students $(n=66)$ before, during, and after a private and a public performance and (b) the moderating effect of music performance anxiety (MPA).

Results: Heart rate (HR), minute ventilation $\left(\mathrm{V}_{\mathrm{E}}\right)$, and all affective and somatic self-report variables increased in the public session compared to the private session. Furthermore, the activation of all variables was stronger during the performances than before or after. Differences between phases were larger in the public than in the private session for $H R, V_{E}$, total breath duration, anxiety, and trembling. Furthermore, while higher MPA scores were associated with higher scores and with larger changes between sessions and phases for selfreports, this association was less coherent for physiological variables. Finally, self-reported intra-individual performance improvements or deteriorations were not associated with MPA.

Conclusion: This study makes a novel contribution by showing how the presence of an audience influences low- and high-anxious musicians' psychophysiological responding before, during and after performing. Overall, the findings are more consistent with models of anxiety that emphasize the importance of cognitive rather than physiological factors in MPA.
\end{abstract}

Keywords: psychophysiology; musicians; music performance anxiety (MPA); stage fright; quality 


\section{Introduction}

Research on the affective and physiological manifestations of performance stress in musicians has strongly focused on the phases shortly before and/or during a performance. Various studies have shown an increase in the affective and physiological arousal before and/or during a public performance compared to non-public performances (i.e., practice session, rehearsal) (e.g., Brotons, 1994; LeBlanc, Jin, Obert, \& Siivola, 1997; Yoshie, Kudo, Murakoshi, \& Ohtsuki, 2009). Also self-reported symptoms of physiological arousal such as palpitations, perspiration, dry mouth, trembling, and disturbances in breathing patterns have been reported to occur in musicians before public performances (Plaut, 1988; Steptoe, 1989, 2001; Studer, Danuser, Hildebrandt, Arial, \& Gomez, 2011; Wesner, Noyes, \& Davis, 1990; Wolfe, 1989). Since the period after the music performance has received only limited attention, there is a lack of understanding of the affective and physiological manifestations of performance stress in a comprehensive time perspective including the phases before, during, and after a performance. In order to investigate stress reactions as a whole, it is important to assess both the reactivity of affective and physiological parameters, i.e., the changes from before to during a performance, and their recovery. Recovery can be defined as "a post stress rest period that provides information about the degree to which the reactivity in the physiological and psychological parameters being measured persists after the stressor has ended" (Linden, Earle, Gerin, \& Christenfeld, 1997, pp. 117-118).

As in all performance contexts, performance anxiety in musicians - called music performance anxiety (MPA) or stage fright (but see Brodsky (1996) and Studer et al. (2011) for a discussion of the nomenclature) - is a widespread phenomenon (Kenny, Davis, \& Oates, 2004). The first study testing low- and high-anxious musicians and assessing a physiological parameter (i.e., heart rate $(\mathrm{HR})$ ) before, during, and after a private (audience-free) 
performance and a public one was carried out by Fredrikson and Gunnarsson (1992). To our knowledge, there are no other comparable studies to date. Fredrikson and Gunnarsson (1992) reported that HR was higher in the public than in the private condition. Furthermore, HR was higher during than before or after the performances. Finally, the HR increase between before and during the performance was greater in the public session than in the private session. With respect to MPA, these authors found that high-anxious musicians had higher HR than lowanxious musicians during the public performance phase compared to the private performance phase. They did not report whether there were differences in the recovery phase depending on the anxiety level or the session.

It is not clear yet whether anxiety has a moderating effect on the psychophysiological responding during recovery. Based on findings on other anxiety disorders than MPA (i.e., panic disorder, generalized anxiety disorder), there is evidence that the impact of anxiety on the psychophysiological responding may be more obvious during the recovery phase than before or during a stressful situation (Roth, Wilhelm, \& Trabert, 1998; Wilhelm, Trabert, \& Roth, 2001). However, Mauss, Wilhelm and Gross (2003) did not find any differences in the physiological recovery among high- and low trait socially anxious persons after a public speaking task.

In the field of music performance, HR is the most often assessed indicator of physiological arousal (Abel \& Larkin, 1990; Brotons, 1994; Craske \& Craig, 1984; Fredrikson \& Gunnarsson, 1992; LeBlanc et al., 1997; Mulcahy et al., 1990; Yoshie et al., 2009; Yoshie, Kudo, \& Ohtsuki, 2008). Other physiological indices such as skin conductance (Yoshie et al., 2009; Yoshie et al., 2008), blood pressure (Abel \& Larkin, 1990), hormone levels (Fredrikson \& Gunnarsson, 1992), and muscle tension (Yoshie et al., 2009; Yoshie et al., 2008) were assessed less often. Also respiration has been rarely investigated and the focus was exclusively on respiratory rate (Craske \& Craig, 1984). This is unfortunate given the evidence 
for the association between respiration and affect and anxiety (Abelson, Khan, \& Giardino, 2010; Boiten, Frijda, \& Wientjes, 1994) and more specifically between self-reported breathing-related symptoms and MPA (Studer, Danuser, et al., 2011; Widmer, Conway, Cohen, \& Davies, 1997). In a recent publication, we reported how affective experience, somatic symptoms, and cardiorespiratory behavior change prior to a private and a public performance as a function of MPA (Studer et al., 2012). Self-reported affect and somatic symptoms, HR, and various respiratory parameters all increased before the public performance compared to before the private performance. Whereas the increases in the selfreports were higher in high- as compared to low-anxious musicians, MPA had no moderating effect on the physiological variables with the exception of the partial pressure of end-tidal $\mathrm{CO}_{2}\left(\mathrm{PetCO}_{2}\right)$. PetCO $\mathrm{C}_{2}$ increased from the private to the public session for musicians with low MPA levels and decreased for musicians with high MPA levels. In summary, respiration was stimulated before the public performance compared to the private performance. Respiration adjusted to the requirements of the music and the instrument is - especially for wind instrumentalists and singers - fundamental.

In this article, we report new data from the above-mentioned study (Studer et al., 2012) about the psychophysiological activation during and after the performances. Furthermore, contrary to the dichotomous anxiety classification used by Fredrikson and Gunnarsson (1992), we will assess MPA as a continuous variable. This will allow for a more complete analysis of the association of MPA with the affective and the (self-reported and actual) physiological activation before, during, and after a performance. Finally, we will address an issue that has received limited attention in past research, i.e., the quality of the performance and how it is affected by increased arousal and MPA. Findings on the influence of the performance setting (non stressful vs. stressful) and the anxiety level on the performance quality are somewhat inconsistent. While some researchers reported a decrease in the performance quality from the 
non stressful to the stressful performance situation (Yoshie et al., 2009), others reported no differences (Craske \& Craig, 1984) and still others reported even an increase in performance quality (Hamann \& Sobaje, 1983).

The main goal of this study was to provide a comprehensive view on the dynamics of selfreported variables (anxiety, tension, shortness of breath, difficulty breathing, palpitations, trembling, sweaty hands) and physiological variables ( $\mathrm{HR}, \mathrm{V}_{\mathrm{E}}$, total breath duration $\left(\mathrm{T}_{\mathrm{TOT}}\right)$, and $\mathrm{PetCO}_{2}$ ) before, during and after a private and a public music performance and to investigate the moderating effect of MPA. Based on previous research (Brotons, 1994; Fredrikson \& Gunnarsson, 1992; Studer et al., 2012; Widmer et al., 1997; Yoshie et al., 2009), we hypothesized that musicians show stronger arousal with respect to the physiological variables $\left(\mathrm{HR}, \mathrm{V}_{\mathrm{E}}, \mathrm{T}_{\mathrm{TOT}}\right)$ and the self-report variables during a public performance compared to a private performance (hypothesis 1) and during the performance compared to before or after the performance (hypothesis 2). We also expected to find stronger physiological and selfreported arousal in musicians with higher usual levels of MPA as compared to musicians with lower usual levels of MPA (hypothesis 3). Furthermore, we hypothesized that the changes in the physiological and self-reported arousal between phases are larger in the public session than in the private session (hypothesis 4), that musicians with higher usual levels of MPA as compared to musicians with lower usual levels of MPA show a larger increase in self-reported and physiological arousal between the private and the public session (hypothesis 5) and larger changes between phases in the public session as compared to the private session (hypothesis 6). We also hypothesized that the session-dependent changes between phases are larger with increasing MPA levels (hypothesis 7).

The secondary goal of this study was to examine how the quality of the performance is affected by MPA. Given the mixed evidence concerning the association between MPA and the quality of performance, we analyzed this issue in an exploratory way. 


\section{Psychophysiological Activation in Music Students}

\section{Methods}

Data presented in this paper were collected during an experimental study published in Studer et al. (2012). This previous publication focused on the phase before a private and a public music performance to analyze in detail the anticipatory performance anxiety. The present paper extends this previous report by additionally analyzing the phases during and after the performances.

\subsection{Participants}

Seventy-four students from six Swiss music universities participated in this study. Eight musicians had to be excluded because they did not participate in all measurement sessions, because they were not compliant with the experimenter's instructions, or due to technical failure. Thus, the final sample was composed of 66 students (59\% female). Participants were 16-30 years old $(M=23.2 ; S D=3.4)$ and their professional music education at the university level ranged between the first and eighth year. The sample composition was $18 \%$ singers, $27 \%$ wind instrumentalists, $30 \%$ string players, $18 \%$ pianists, and $7 \%$ miscellaneous.

\subsection{Procedure}

All participants were tested individually in three sessions: baseline session, private session, and public session, separated by approximately one week each. The goal of the baseline session was to familiarize the participants with the measurement devices, the experimenter, and the study design as well as to assess the baseline values for the dependent variables. The participants did not have to perform in the baseline session. For the private and the public session they performed the same « moderately difficult» musical pieces, which they were free to choose. The private session always preceded the public session to mirror as much as possible real performance situations, i.e., rehearsal before concert (cf. Studer et al., 2012). Both sessions encompassed a warm-up phase to tune the instrument or the voice, a pre- 
performance phase (in a preparation room), a performance phase (in an adjacent concert room), and a post-performance phase (again in the preparation room). Each phase lasted for approximately 10 minutes. The participants were sitting during each phase with the exception of singers, wind instrumentalists, violinists, and a double-bass player who were standing during the private and the public performance phase. During the pre- and the postperformance phases, the musicians were left alone and they were allowed to read. The private and the public session were identical with the following exceptions: In the public session, an audience composed by approximately ten persons was present. Furthermore, the public performance was audio recorded, and the musicians were told that two experts in the audience would evaluate the performance.

\subsection{Measurements}

\subsubsection{Assessment of MPA}

MPA can be considered as state anxiety with trait character. It is reasonable to assume that MPA remains stable for identical performance situations - at least over a certain time period. Therefore, we assessed the students' usual MPA level using the state scale of Spielberger's State Trait Anxiety Inventory (STAI-S) (Spielberger, Gorsuch, \& Lushene, 1970). The instructions were slightly adapted as done previously (Widmer et al., 1997) and asked how they had felt before recent public solo performances they considered important. The STAI-S consists of 20 items addressing apprehensive feelings of anxiety. Each item was rated on a 4point Likert scale (1 "not at all" to 4 "very much so"). The score of this questionnaire can range from 20 (no anxiety) to 80 (extreme anxiety). The STAI-S was chosen for several reasons. First, almost all studies on MPA have used different ad hoc questionnaires; thus, there is no criterion standard questionnaire to assess MPA. By contrast, the STAI-S although somewhat unspecific - has been widely used in research on (performance) anxiety 
(Brodsky, 1996; Widmer et al., 1997). Second, the STAI-S allowed us to assess the affective dimension, which is the central component of the experience of MPA in many musicians (Steptoe, 2001), as continuous variable. The score of the STAI-S is referred to as "MPA score" throughout the article.

\subsubsection{Physiological measures}

From a total of 13 assessed cardiorespiratory variables, we have maintained four key variables, i.e., $\mathrm{HR}, \mathrm{V}_{\mathrm{E}}, \mathrm{T}_{\mathrm{TOT}}$, and $\mathrm{PetCO}_{2}$. $\mathrm{HR}$ was chosen as cardiac parameter, $\mathrm{V}_{\mathrm{E}}$ as respiratory flow parameter, $\mathrm{T}_{\mathrm{TOT}}$ as respiratory timing parameter, and $\mathrm{PetCO}_{2}$ as indicator for hyperventilation (Van Diest, Bradley, Guerra, Van den Bergh, \& Lang, 2009). Additionally, data of the accelerometer (ACC) are reported to control for the physical activation. Physiological parameters were sampled continuously over all the assessment periods, except PetCO ${ }_{2}$, which was not sampled during the performance phase, because the nasal assessment would have interfered with the singers' and wind instrumentalists' ability to perform and since other instrumentalists do not breathe exclusively through the nose while performing.

The electrocardiogram (ECG), the respiratory flow and time parameters, as well as the ACC data were assessed with the LifeShirt ${ }^{\circledR}$ system, a non invasive ambulatory assessment device (VivoMetrics Inc., Ventura, CA, USA; see Wilhelm, Pfaltz, and Grossman (2006) for a detailed description of the system). This snugly fitting T-shirt uses respiratory inductive plethysmography, which is the criterion standard for unobtrusive respiratory monitoring. Data were sampled at $200 \mathrm{~Hz}$ for the ECG and at $50 \mathrm{~Hz}$ for respiratory timing and volume parameters. PetCO $\mathrm{P}_{2}$ was recorded by means of a nasal canula connected to a non-dispersive infrared $\mathrm{CO}_{2}$ monitor with a resolution of $1 \mathrm{~mm} \mathrm{Hg}$, an accuracy of $2 \mathrm{~mm} \mathrm{Hg}$, a sampling flow rate of $50 \mathrm{~mL} / \mathrm{min}$, and a sampling rate of $40 \mathrm{~Hz}$ (Microcap Handheld Capnograph, Oridion Medical 1987Ltd., Jerusalem). 


\subsubsection{Self-report measures}

The affective experience was assessed with two single-items, i.e., "anxiety" and "tension". The perceived physiological activation (i.e., somatic symptoms) was assessed with five single-items, i.e., "difficulty in breathing deeply", "shortness of breath", "palpitations", "trembling", and "sweaty hands". Each item was rated on an 11-point Likert scale ranging from 1 "not at all" to 11 "extremely". These self-reports were assessed (a) at the beginning and at the end of the pre-performance phase, (b) at the beginning of the post-performance phase to rate retrospectively the affective experience and the perceived physiological activation during the performance, and (c) at the end of the post-performance phase. Since the differences in the ratings between the beginning of the pre-performance phase and its end were not significant, they were considered as a repeated measure.

\subsubsection{Self-rated quality of the performance and effort}

At the end of the post-performance phase in the private and the public condition, all musicians were asked to rate the quality of their performance on a scale from 1 "very bad" to 11 "excellent" and the effort they put into the performance on a scale from 1 "none" to 11 "very much".

\subsection{Data editing}

The ECG and $\mathrm{PetCO}_{2}$ data were analyzed using ANSLAB (Wilhelm \& Peyk, 2006). The respiratory flow and timing parameters were analyzed with VivoLogic, provided by VivoMetrics Inc. (Ventura, CA, USA). $\mathrm{V}_{\mathrm{E}}$ was determined with an $800 \mathrm{ml}$ fixed volume bag calibration. This calibration was carried out in the sitting and standing position and applied to the respective position of the musicians. For all physiological measures, data were averaged over the 10-minute assessment period of each session. For a more detailed description of the data editing see Studer et al. (2012). 


\subsection{Statistical methods}

All analyses were performed using Stata version 11.0 for Windows (Stata Statistical Software, StataCorp LP, Texas). For the regression analyses of right-skewed continuous variables $\left(\mathrm{V}_{\mathrm{E}}\right.$ and $\mathrm{T}_{\mathrm{TOT}}$ ), the latter were logarithmically transformed in order to achieve approximate normality. For the statistical analyses, the physiological data were averaged over the 10-min pre-performance, performance, and post-performance periods, respectively. The physiological variables and the psychological variables were analyzed with generalized linear mixed models with a subject-specific random intercept. This statistical method allowed us to examine jointly the effect of the independent variables at the unchanging subject level (MPA score, instrument group, gender) and at the condition level (session, phase, and physical activation (ACC)) as well as the interactions between Phase $\mathrm{x}$ Session, Session x MPA, Phase x MPA, and Phase $\mathrm{x}$ Session x MPA. Since the self-report variables were recorded on an ordinal scale and were, therefore, not amenable to the standard linear mixed model analysis, we used for them the ordered logistic mixed model analysis. This model is a direct generalization of the ordinary two-outcome logistic model. An underlying score is estimated as a linear function of the independent variables and a set of cut points. The parameters estimate of the model can be interpreted as a log-odds ratio assumed to be identical for all cut points (Rabe-Hesketh \& Skrondal, 2008).

The modelling strategy proceeded as follows: the first regression model (M1), used to test hypotheses 1-3, included all main effects of interest (session, phase, MPA score), additionally controlling for gender, instrument group, and $\mathrm{ACC}^{1}$. Subsequently, four interaction models were fitted sequentially: The first interaction model (M2) used to test hypothesis 4 added the Phase $\mathrm{x}$ Session interaction to M1. The second interaction model (M3) used to test hypothesis

\footnotetext{
${ }^{1}$ Independent variables were coded as follows: session: private $=0$ public $=1$; phase: pre-performance $=0$, performance=1, post-performance $=2$; $M P A$ score=continuous; gender: women=0, men=1; instrument group: non wind instrumentalists $=0$, wind instrumentalists $=1 ; A C C=$ continuous
} 
5 added the Session x MPA interaction to M2. The third interaction model (M4) used to test hypothesis 6 added the Phase x MPA interaction to M3; and finally, the fourth interaction model (M5) used to test hypothesis 7 added the Phase $\mathrm{x}$ Session $\mathrm{x}$ MPA third-order interaction to M4. Regression analyses display the results always with respect to a reference group within each independent variable. Thus, in order to show the global effect of Phase, Phase x Session, Phase x MPA, and Phase x Session x MPA, we additionally performed postestimation Wald tests (indicated by the $\chi 2$ statistics in the text). The variable "phase" was further analyzed by pairwise post-estimation comparisons of each variable level (i.e., before, during, and after the performance) with multiplicity adjustment according to Sidak. This procedure allowed us to compare the various phases within and across sessions. To report the Phase $\mathrm{x}$ Session interaction effect in an intelligible way, we additionally report the differences in change scores between phases over the sessions. Finally, to investigate the self-rated quality of the performance and its association with the performance condition (private vs. public) and the MPA score, the Pearson correlation coefficients were calculated. 


\section{Psychophysiological Activation in Music Students}

\section{Results}

The descriptive results for each phase of the private and the public session are given in Table 1. Since musicians with lower MPA scores and musicians with higher MPA scores did not differ from each other with respect to any of the self-report or physiological variables during the baseline session (Studer et al., 2012), this session is not taken into account any further. The results of the regression analyses for the physiological variables and the self-report variables are given in Table 2 and Table 3, respectively. The graphic representations of the physiological variables and a selection of the self-report variables are given in Figure 1.

The analyses of "difficulty breathing", "tension", and "sweaty hands" yielded qualitatively comparable results. The same is true for "palpitations" and "shortness of breath". In order to avoid repetitions, we present only one variable of these groups, i.e., "difficulty breathing" and "palpitations".

\subsection{Main effects for session, phase, and MPA}

$\mathrm{HR}, \mathrm{V}_{\mathrm{E}}$ and all self-report variables showed stronger activation during the public session as compared to the private session, thereby confirming hypothesis 1 on the session effect for these variables. Hypothesis 2 on the phase effect was confirmed for all physiological and selfreport variables $\left(\mathrm{HR}: \chi^{2}(2)=370.75 ; \mathrm{V}_{\mathrm{E}}: \chi^{2}(2)=775.37 ; \mathrm{T}_{\mathrm{TOT}}: \chi^{2}(2)=44.75\right.$; “anxiety": $\chi^{2}(2)$

$=115.82$; "difficulty breathing": $\chi^{2}(2)=55.52$; "trembling": $\chi^{2}(2)=44.82$; "palpitations": $\chi^{2}(2)=89.15$; all $\left.p \mathrm{~s}<.001\right)$. HR, $\mathrm{V}_{\mathrm{E}}$, and all self-report variables were higher, respectively lower for $\mathrm{T}_{\mathrm{TOT}}$, during the performance than before and after. $\mathrm{PetCO}_{2}$, which was not measured during performance, showed lower values after the performance than before the performance. Whereas the MPA score had no significant effect on any of the assessed physiological variables, the self-report ratings significantly increased with increasing MPA 
scores. Thus, hypothesis 3 was confirmed for the self-report variables, with the exception of "palpitations" $(p s<.05)$.

\subsection{Interaction effect: Phase $x$ Session}

Hypothesis 4 on the Phase $x$ Session interaction was confirmed for $\operatorname{HR}\left(\chi^{2}(2)=132.6, p<\right.$ $.001), \mathrm{V}_{\mathrm{E}}\left(\chi^{2}(2)=6.27, p<.05\right), \mathrm{T}_{\mathrm{TOT}}\left(\chi^{2}(2)=7.43, p<.05\right)$, "anxiety" $\left(\chi^{2}(2)=10.45, p<\right.$ $.01)$, and "trembling" $\left(\chi^{2}(2)=19.33, p<.01\right)$. The effect of the phase was thus not uniform across the sessions for these variables. Whereas HR was significantly higher in each phase of the public session as compared to the corresponding phase in the private session (before: +7.7 bpm, during: $+28.1 \mathrm{bpm}$, after: $+8.4 \mathrm{bpm} ; \mathrm{ps}<.001)$, the biggest increase was observed between the two performance phases. Post-hoc analysis revealed that the interaction effect was due to both the larger increase from the pre-performance to the performance phase (private: $+21.6 \mathrm{bpm}$; public: $+42.0 \mathrm{bpm}$ ) and the larger decrease from the performance to the post-performance phase (private: $-23.4 \mathrm{bpm}$; public: $-43.1 \mathrm{bpm}$ ) in the public session compared to the private session $(p<.001)$. Also $\mathrm{V}_{\mathrm{E}}$ was higher before and during the public performance as compared to the corresponding phases in the private session (before: $+11 \%$, during: $+19 \% ; p<.01, p<.001$, respectively). The post-performance phase was not significantly different between the two sessions. Post-hoc analysis revealed that the interaction effect was due to the stronger decrease from the performance to the postperformance phase in the public session (65\% decrease) compared to the private session $(60 \%$ decrease $)(p<.05)$. $\mathrm{T}_{\mathrm{TOT}}$ was significantly shorter during the public performance as compared to during the private performance $(p<.05)$. $\mathrm{T}_{\text {TOт }}$ showed a larger decrease from the preperformance phase to the performance in the public session compared to the private session ($29 \%$ vs. $-17 \% ; p<.05)$ 
Also the self-report variables were significantly higher before, during, and after the public performance as compared to the corresponding phase in the private performance (all $\mathrm{ps}<.05$ with the exception of "anxiety" after the performance). Although the differences in the selfratings after the performance between the private and the public session were significant, they were of small magnitude. Post-hoc analyses for the two self-report variables with a significant Phase $\mathrm{x}$ Session effect showed that the decrease for "anxiety" from before to after the performance and from during to after the performance $(p s<.01)$ was stronger in the public than in the private session. For "trembling", the increase from before to during the performance and the decrease from during to after the performance were stronger in the public than in the private session $(p s<.05)$.

\subsection{Interaction effects: Session $x$ MPA and Phase $x$ MPA}

Hypothesis 5 on the Session x MPA interaction was confirmed for $\mathrm{PetCO}_{2}$, "anxiety", and "difficulty breathing". The PetCO $\mathrm{P}_{2}$ of the least anxious musicians increased from the private to the public session, whereas the $\mathrm{PetCO}_{2}$ of the most anxious musicians decreased. This effect is illustrated in Figure 1 and described in detail in Studer et al. (2012) for the preperformance phase. Also for the self-report variables, the main effect of the session was amplified by increasing MPA scores, with the exception of "trembling" and "palpitations".

There was a significant Phase x MPA effect for $\mathrm{V}_{\mathrm{E}}\left(\chi^{2}(2)=16.59, \mathrm{p}<.001\right)$, "anxiety" $\left(\chi^{2}(2)\right.$ $=10.48, p<.01)$ and "palpitations" $\left(\chi^{2}(2)=8.92, p<.05\right)$. Hypothesis 6 was, thus, confirmed for these variables. Whereas $\mathrm{V}_{\mathrm{E}}$ was significantly higher with increasing MPA before the performance $(p<.05)$ and marginally higher after the performance $(p=.07)$, MPA showed no effect on $V_{E}$ during performance. Thus, the Phase $x$ MPA effect was manifest in (a) a less steep increase from the pre-performance to the performance phase with increasing MPA 
scores $(p<.001)$ and $(b)$ a less steep decrease from the performance to the post-performance phase with increasing MPA scores $(p<.01)$.

Finally, there was no significant Phase $\mathrm{x}$ Session $\mathrm{x}$ MPA interaction for any physiological or self-report variable. Hypothesis 7 was, therefore, completely rejected.

\subsection{Self-rated quality of the performance and effort}

The musicians made an effort to play at their best in both sessions (private: $M=8.2(S D=$ $2.0)$; public: $M=9.2(S D=1.5))$. Overall, the self-ratings of the private and the public performance quality were not significantly different (private session: $M=6.1(S D=1.8)$ vs. public session: $M=6.2(S D=2.1), t(63)=-0.40, p=.69$, two-sided $)$. Twenty-eight musicians rated their public performance as being better than their private performance, whereas 18 rated their private performance as being better than their public performance. Eighteen musicians rated their performance identically in both the private and the public condition. The performance rating was only weakly, though significantly, correlated with the MPA score in both the private session $(r=-.26 ; p<.05)$ and the public session $(r=-.33 ; p<.01)$. The correlation between MPA and the change score of the self-rating of the performance, i.e., the difference between the private and the public performance, was even weaker and not significant anymore $(r=-.10 ; p=.41)$. 


\section{Discussion}

The main goal of the present study was to investigate the physiological activation and the selfreported affective experience and somatic symptoms during performance stress in musicians in a comprehensive time perspective. To this end, we analyzed the phases before, during, and after a private and a public performance. Furthermore, we investigated the moderating effect of MPA on the physiological activation and the self-reported variables. Finally, we also investigated the association between the musicians' self-rating of the performance quality and their MPA score.

$\mathrm{HR}$ and $\mathrm{V}_{\mathrm{E}}$ showed a stronger activation during the public session than during the private one. Furthermore, their activation and the one of $\mathrm{T}_{\mathrm{TOT}}$ were stronger during the performances than before or after. These results are in line with previous research (Brotons, 1994; Fredrikson \& Gunnarsson, 1992; LeBlanc et al., 1997; Mulcahy et al., 1990; Spahn, Echternach, Zander, Voltmer, \& Richter, 2010; Yoshie et al., 2009). Previous studies reported that the HR of musicians was 99 - 112 bpm during a low-stress performance (practice, rehearsal) (Brotons, 1994; LeBlanc et al., 1997; Yoshie et al., 2009). This level of activation during musical performance is in between $\mathrm{HR}$ at rest in healthy adults $(70 \mathrm{bpm})$ and $\mathrm{HR}$ during moderate to heavy exercise (150-180 bpm) (McArdle, Katch, \& Katch, 2006). Thus, part of the increased physiological activation we observed during the public performance can be explained by the physical demands of musical performance. The physical effort due to performing, however, does not explain why the activation for $\mathrm{HR}$ and $\mathrm{V}_{\mathrm{E}}$ was stronger during the public performance than during the private one $\left(+28.1 \mathrm{bpm}\right.$ for $\mathrm{HR}$ and $+2.77 \mathrm{l} / \mathrm{min}$ for $\left.\mathrm{V}_{\mathrm{E}}\right)$. Furthermore, given the fact that neither the Session $\mathrm{x}$ MPA interaction nor the Phase $\mathrm{x}$ Session $\mathrm{x}$ MPA interaction were significant, also MPA cannot explain the higher physiological activation during the public performance. Also globally, there was no 
association between the physiological variables and the MPA score. The same lack of association between physiological activation and anxiety was previously reported for HR, skin conductance level, and respiratory sinus arrhythmia in high trait socially anxious individuals vs. low trait socially anxious individuals in a public speaking task (Mauss et al., 2003).

Compared to during the private performance, $\mathrm{HR}$ and $\mathrm{V}_{\mathrm{E}}$ were significantly higher during the public performance and $\mathrm{T}_{\text {Tот }}$ was significantly smaller. Although being significant, the observed changes in $\mathrm{T}_{\mathrm{TOT}}$ during the public performance were of rather small magnitude contrary to the changes in $\mathrm{HR}$ and $\mathrm{V}_{\mathrm{E}}$. This may be due to the fact that $\mathrm{T}_{\mathrm{TOT}}$ is bound more tightly to the demands of a musical piece than other physiological variables. This applies particularly to wind instrumentalists and singers. For these instrument types breathing is strongly determined by the music. Nevertheless, $\mathrm{T}_{\mathrm{TOT}}$ was slightly shorter in the public performance phase than in the private one. In a previous study on pianists, Yoshie et al. (Yoshie et al., 2009) reported a tendency to play faster in a public competition condition than in a rehearsal condition without audience. For wind instrumentalists and singers, faster playing goes along with an increase in the respiratory rate. This link between increased tempo and decreased $\mathrm{T}_{\mathrm{TOT}}$ might also apply - although to a lesser degree - to the other instrument groups. Previous studies have shown that the mere listening to music induced significant increases in breathing rate with faster musical tempi. This result was even more obvious in musicians than in non-musicians (Bernardi, Porta, \& Sleight, 2006). Furthermore, Ebert et al. (2002) reported an association between meter rate, tempo, and breathing rate. Thus, future studies would benefit from taking into account the association between breathing rate and tempo.

PetCO$_{2}$ values after the performance were significantly lower than before, although only slightly (see Figure 1). This might be due to a tendency to breathe in excess of metabolic 
requirements (i.e., hyperventilate) during the performances. To confirm this hypothesis, future studies should assess $\mathrm{PetCO}_{2}$ during the performance. Furthermore, there was a difference in $\mathrm{PetCO}_{2}$ values between the private and the public session depending on the MPA level of the musician. More precisely, $\mathrm{PetCO}_{2}$ increased from the private to the public session for lowanxious musicians whereas it decreased for high-anxious musicians. Again, the decrease from the stress-free to the distressing performance situation may be due to an underlying hyperventilation problem in high-anxious musicians. This phenomenon is discussed in detail for the phase before the performance in Studer et al. (2012).

The MPA level also affected the changes between phases in $V_{E}$. In high-anxious musicians compared to low-anxious musicians $\mathrm{V}_{\mathrm{E}}$ increased less strongly between the pre-performance phase and the performance phase and decreased less strongly between the performance and the post-performance phase. This was due to the fact that high-anxious musicians had higher $\mathrm{V}_{\mathrm{E}}$ than low-anxious musicians before and after the performance but were comparable during the performances. One could assume that $\mathrm{V}_{\mathrm{E}}$ is by default higher in more anxious musicians than in less anxious musicians. However, given that $V_{E}$ was comparable in higher and lower anxious musicians during the baseline (data not shown) and during performance, this conclusion does not hold. The investigation of worry and post-event rumination and their influence on respiration might elucidate this finding in future studies (Kenny, 2011).

In line with the findings of Ballegaard et al. (2009) and Fredrikson and Gunnarsson (1992), our results show the expected pattern of psychophysiological responding before, during, and after acute stress, i.e., activation from before to during the performance phase and recovery from during to after the performance phase (see also McEwen \& Seeman, 2003). However, despite significant decreases in the physiological activation from the public performance phase to the post-performance phase, HR did not decrease to the post-performance level of the stress-free private session. Nevertheless, the recovery was in absolute terms stronger in the 
public session than in the private one. In future studies, it would be interesting to investigate how long it takes for the musicians after a public performance to reach the post-performance level of a stress-free performance.

As for $\mathrm{HR}$ and $\mathrm{V}_{\mathrm{E}}$, the ratings for all self-report variables were (a) higher in the public session than in the private session and (b) higher during the performance as compared to before and after it. Thus, they also showed the expected pattern of activation and recovery from before to during and from during to after acute stress. The finding of increased self-reported measures during the performances is somewhat contradictory to Salmon's assertion that anxious apprehensions are strongest before rather than during a public performance (Salmon, 1990). However, it is not clear which time period Salmon termed "before performance". "Before performance" might refer to the period immediately prior to the performance when the musicians walk on stage and are confronted with the audience rather than to the period ten minutes before the performance. Furthermore, all self-report variables were consistently associated with the MPA score (i.e., the STAI-S score), showing that higher anxious musicians reported globally higher ratings for the affective experience and for the selfperceived somatic symptoms. Contrary to the physiological variables, MPA amplified the session effect in all self-report variables with the exception of "trembling". The main effect of the phase was amplified only for some self-report variables ("anxiety" and "palpitations").

Clearly, whereas there was a consistent association between MPA and self-report variables, the association between MPA and the physiological variables was much less consistent. This finding is in line with previous studies showing that musicians with a high level of affective performance anxiety do not globally differ from low-anxious musicians at the physiological level (Craske \& Craig, 1984; Fredrikson \& Gunnarsson, 1992). The absence of physiological differences between high- and low-anxious subjects was also reported for other forms of anxiety (Anderson \& Hope, 2009; Grossman, Wilhelm, Kawachi, \& Sparrow, 2001; Mauss et 
al., 2003; Mauss, Wilhelm, \& Gross, 2004). This is consistent with models of social anxiety which emphasize the importance of cognitive factors (such as attentional focus and dysfunctional appraisal) in the experience of anxiety (Clark \& McManus, 2002; Leary \& Kowalski, 1995). Thus, low-anxious musicians may focus their attention on the music pieces and their performance, whereas high anxious musicians focus their attention at least partly on bodily manifestations - especially during the performance phase when the self-reported symptoms are highest. In conclusion, the observed changes in the physiological activation are primarily attributable to the performance stress rather than to trait MPA. Spahn et al. (2010, p. 81) concluded in this respect that "physiological arousal may be a necessary condition for MPA, but it is not a sufficient explanation”.

When interpreting the above discussed results the likelihood of Type I errors should be kept in mind given the large number of statistical tests that were carried out. However, the response pattern for the main effects of all variables and for the Session x MPA interaction effects of the self-report variables is coherent and repeated. Also for those effects with low to very low $p$-values Type I errors are unlikely.

Finally, the musicians rated their performance as being worse with increasing levels of usual MPA in the private and the public sessions. However, the correlation between the self-rated quality of the performance and the MPA score was only weak. Furthermore, there was no evidence that intra-individual performance improvements or deteriorations from the private to the public session were associated with the MPA score. Quality ratings by the musician him/herself yield valuable information given that the musician knows best which level of performance s/he is capable to achieve. Also, musicians' opinion on their own performance is highly important for their personal satisfaction. However, personal ratings might be influenced by individual expectations and character traits such as perfectionism. Therefore, further studies might want to compare experts' ratings with musicians' ratings. In this case, 
Psychophysiological Activation in Music Students

attention should be paid to the fact that expert ratings are prone to be biased depending on whether the rater sees or only hears the performer (Fredrikson \& Gunnarsson, 1992). 
Psychophysiological Activation in Music Students

\section{Acknowledgements}

We are grateful to the Swiss National Science Foundation, which funded the present study (subsidy $\mathrm{N}^{\circ}$ 100013-112520), and to the Swiss University Centre for Music Physiology for their kind support. The authors wish to thank the music universities and the music schools "Crescendo" and "Institut de Ribaupierre" for their precious help as well as Christa Flückiger for her assistance in gathering the research data. 
References

Abel, L., \& Larkin, T. (1990). Anticipation of Performance among Musicians: Physiological Arousal, Confidence, and State-Anxiety. Psychology of Music, 18, 171-182.

Abelson, J. L., Khan, S., \& Giardino, N. (2010). HPA axis, respiration and the airways in stress-A review in search of intersections. Biological Psychology, 84(1), 57-65. doi: DOI 10.1016/j.biopsycho.2010.01.021

Anderson, E. R., \& Hope, D. A. (2009). The relationship among social phobia, objective and perceived physiological reactivity, and anxiety sensitivity in an adolescent population. [Research Support, N.I.H., Extramural]. Journal of Anxiety Disorders, 23(1), 18-26. doi: 10.1016/j.janxdis.2008.03.011

Ballegaard, S., Karpatschof, B., Trojaborg, W., Hansen, A. M., Magnusson, G., \& Petersen, P. B. (2009). A simple and objective marker for stress. Scandinavian Journal of Clinical \& Laboratory Investigation, 69(6), 713-721. doi: DOI 10.1080/00365510903042734;PII 912577784

Bernardi, L., Porta, C., \& Sleight, P. (2006). Cardiovascular, cerebrovascular, and respiratory changes induced by different types of music in musicians and non-musicians: the importance of silence. Heart, 92(4), 445-452. doi: 10.1136/hrt.2005.064600

Boiten, F. A., Frijda, N. H., \& Wientjes, C. J. E. (1994). Emotions and Respiratory Patterns - Review and Critical Analysis. International Journal of Psychophysiology, 17(2), 103-128.

Brodsky, W. (1996). Music Performance Anxiety Reconceptualized: A Critique of Current Research Practices and Findings. Medical Problems of Performing Artists, 11, 88-98.

Brotons, M. (1994). Effects of Performing Conditions on Music Performance Anxiety and Performance Quality. Journal of Music Therapy, 31(1), 63-81.

Clark, D. M., \& McManus, F. (2002). Information processing in social phobia. Biological Psychiatry, 51(1), 92-100.

Craske, M. G., \& Craig, K. D. (1984). Musical Performance Anxiety - the 3-Systems Model and SelfEfficacy Theory. Behaviour Research and Therapy, 22(3), 267-280.

Ebert, D., Hefter, H., Binkofski, F., \& Freund, H. J. (2002). Coordination between breathing and mental grouping of pianistic finger movements. [Research Support, Non-U.S. Gov't]. Percept Mot Skills, 95(2), 339-353.

Fredrikson, M., \& Gunnarsson, R. (1992). Psychobiology of Stage Fright: The Effect of Public Performance on Neuroendocrine, Cardiovascular and Subjective Reactions. Biological Psychology, 33(1), 51-61.

Grossman, P., Wilhelm, F. H., Kawachi, I., \& Sparrow, D. (2001). Gender differences in psychophysiological responses to speech stress among older social phobics: Congruence and incongruence between self-evaluative and cardiovascular reactions. Psychosomatic Medicine, 63(5), 765-777.

Hamann, D. L., \& Sobaje, M. (1983). Anxiety and the College Musician: A Study of Performance Conditions and Subject Variables. Psychology of Music, 11, 37-50.

Kenny, D. T. (2011). The Psychology of Music Performance Anxiety (1. ed.). New York: Oxford University Press.

Kenny, D. T., Davis, P., \& Oates, J. (2004). Music performance anxiety and occupational stress amongst opera chorus artists and their relationship with state and trait anxiety and perfectionism. Journal of Anxiety Disorders, 18(6), 757-777. doi: DOI 10.1016/j.janxdis.2003.09.004

Leary, M. R., \& Kowalski, R. M. (1995). The self-presentation model of social phobia. In R. G. Heimberg, M. R. Liebowitz, D. A. Hope \& F. R. Schneier (Eds.), Social phobia: Diagnosis, assessment, and treatment (pp. 94-112). New York: Guilford Press. 
LeBlanc, A., Jin, Y. C., Obert, M., \& Siivola, C. (1997). Effect of audience on music performance anxiety. Journal of Research in Music Education, 45(3), 480-496.

Linden, W., Earle, T. L., Gerin, W., \& Christenfeld, N. (1997). Physiological stress reactivity and recovery: Conceptual siblings separated at birth? Journal of Psychosomatic Research, 42(2), 117-135.

Mauss, I. B., Wilhelm, F. H., \& Gross, J. J. (2003). Autonomic recovery and habituation in social anxiety. Psychophysiology, 40(4), 648-653.

Mauss, I. B., Wilhelm, F. H., \& Gross, J. J. (2004). Is there less to social anxiety than meets the eye? Emotion experience, expression, and bodily responding. Cognition \& Emotion, 18(5), 631662. doi: DOI 10.1080/02699930341000112

McArdle, W., Katch, F., \& Katch, V. (2006). Exercise Physiology: Nutrition, Energy, and Human Performance (6. ed.). Baltimore: Lippincott Williams \& Wilkins.

McEwen, B. S., \& Seeman, T. (2003). Stress and Affect: Applicability of the Concepts of Allostasis and Allostatic Load. In R. J. Davidson, K. R. Scherer \& H. Hill Goldsmith (Eds.), Handbook of Affective Sciences (pp. 1117-1137). New York: Oxford University Press.

Mulcahy, D., Keegan, J., Fingret, A., Wright, C., Park, A., Sparrow, J., . . Fox, K. M. (1990). Circadian Variation of Heart-Rate Is Affected by Environment - A Study of Continuous Electrocardiographic Monitoring in Members of A Symphony-Orchestra. British Heart Journal, 64(6), 388-392.

Plaut, E. A. (1988). Psychotherapy of Performance Anxiety. Medical Problems of Performing Artists, 3(3), 113-118.

Rabe-Hesketh, S., \& Skrondal, A. (2008). Multilevel and Longitudinal Modeling Using Stata (2nd ed.). Texas: Stata Press. (Reprinted from: Not in File).

Roth, W. T., Wilhelm, F. H., \& Trabert, W. (1998). Autonomic instability during relaxation in panic disorder. [Research Support, U.S. Gov't, Non-P.H.S.

Research Support, U.S. Gov't, P.H.S.]. Psychiatry Res, 80(2), 155-164.

Salmon, P. G. (1990). A Psychological Perspective on Musical Performance Anxiety - A Review of the Literature. Medical Problems of Performing Artists, 5(1), 2-11.

Spahn, C., Echternach, M., Zander, M. F., Voltmer, E., \& Richter, B. (2010). Music performance anxiety in opera singers. Logopedics Phoniatrics Vocology, 35(4), 175-182. doi: DOI 10.3109/14015431003720600

Spielberger, C. D., Gorsuch, R. L., \& Lushene, R. E. (1970). STAI Manual for the State-Trait Anxiety Inventory. Palo Alto, CA: Consulting Psychologists Press.

Steptoe, A. (1989). Stress, Coping and Stage Fright in Professional Musicians. Psychology of Music, 17, 3-11.

Steptoe, A. (2001). Negative Emotions in Music Making: The Problem of Performance Anxiety. In P. N. Juslin \& J. A. Sloboda (Eds.), Music and Emotion: Theory and Research (pp. 291-307). New York: Oxford University Press Inc. (Reprinted from: Not in File).

Studer, R., Danuser, B., Hildebrandt, H., Arial, M., \& Gomez, P. (2011). Hyperventilation Complaints in Music Performance Anxiety among Classical Music Students. Journal of Psychosomatic Research, 70(6), 557-564.

Studer, R., Danuser, B., Hildebrandt, H., Arial, M., Wild, P., \& Gomez, P. (2012). Hyperventilation in anticipatory music performance anxiety. [Research Support, Non-U.S. Gov't]. Psychosomatic Medicine, 74(7), 773-782. doi: 10.1097/PSY.0b013e31825e3578

Studer, R., Gomez, P., Hildebrandt, H., Arial, M., \& Danuser, B. (2011). Stage Fright: Its Experience as a Problem and Coping with it. International Archives of Occupational and Environmental Health, 84, 761-771.

Van Diest, I., Bradley, M. M., Guerra, P., Van den Bergh, O., \& Lang, P. J. (2009). Fear-conditioned respiration and its association to cardiac reactivity. Biological Psychology, 80(2), 212-217. doi: DOI 10.1016/j.biopsycho.2008.09.006 
Wesner, R. B., Noyes, R., \& Davis, T. L. (1990). The Occurrence of Performance Anxiety Among Musicians. Journal of Affective Disorders, 18(3), 177-185.

Widmer, S., Conway, A., Cohen, S., \& Davies, P. (1997). Hyperventilation: A correlate and predictor of debilitating performance anxiety in musicians. Medical Problems of Performing Artists, 12(4), 97-106.

Wilhelm, F. H., \& Peyk, P. (2006). Autonomic Nervous System Laboratory (Version 4.0).

Wilhelm, F. H., Trabert, W., \& Roth, W. T. (2001). Physiologic instability in panic disorder and generalized anxiety disorder. Biological Psychiatry, 49(7), 596-605.

Wilhem, F. H., Pfaltz, M. C., \& Grossman, P. (2006). Continuous electronic data capture of physiology, behavior and experience in real life: towards ecological momentary assessment of emotion. Interacting with Computers, 18(2), 171-186. doi: DOI 10.1016/j.intcom.2005.07.001

Wolfe, M. L. (1989). Correlates of Adaptive and Maladaptive Musical Performance Anxiety. Medical Problems of Performing Artists, 4(1), 49-56.

Yoshie, M., Kudo, K., Murakoshi, T., \& Ohtsuki, T. (2009). Music performance anxiety in skilled pianists: effects of social-evaluative performance situation on subjective, autonomic, and electromyographic reactions. Experimental Brain Research, 199(2), 117-126. doi: DOI 10.1007/s00221-009-1979-y

Yoshie, M., Kudo, K., \& Ohtsuki, T. (2008). Effects of Psychological Stress on State Anxiety, Electromyographic Activity, and Arpeggio Performance in Pianists. Medical Problems of Performing Artists, 23(3), 120-132. 


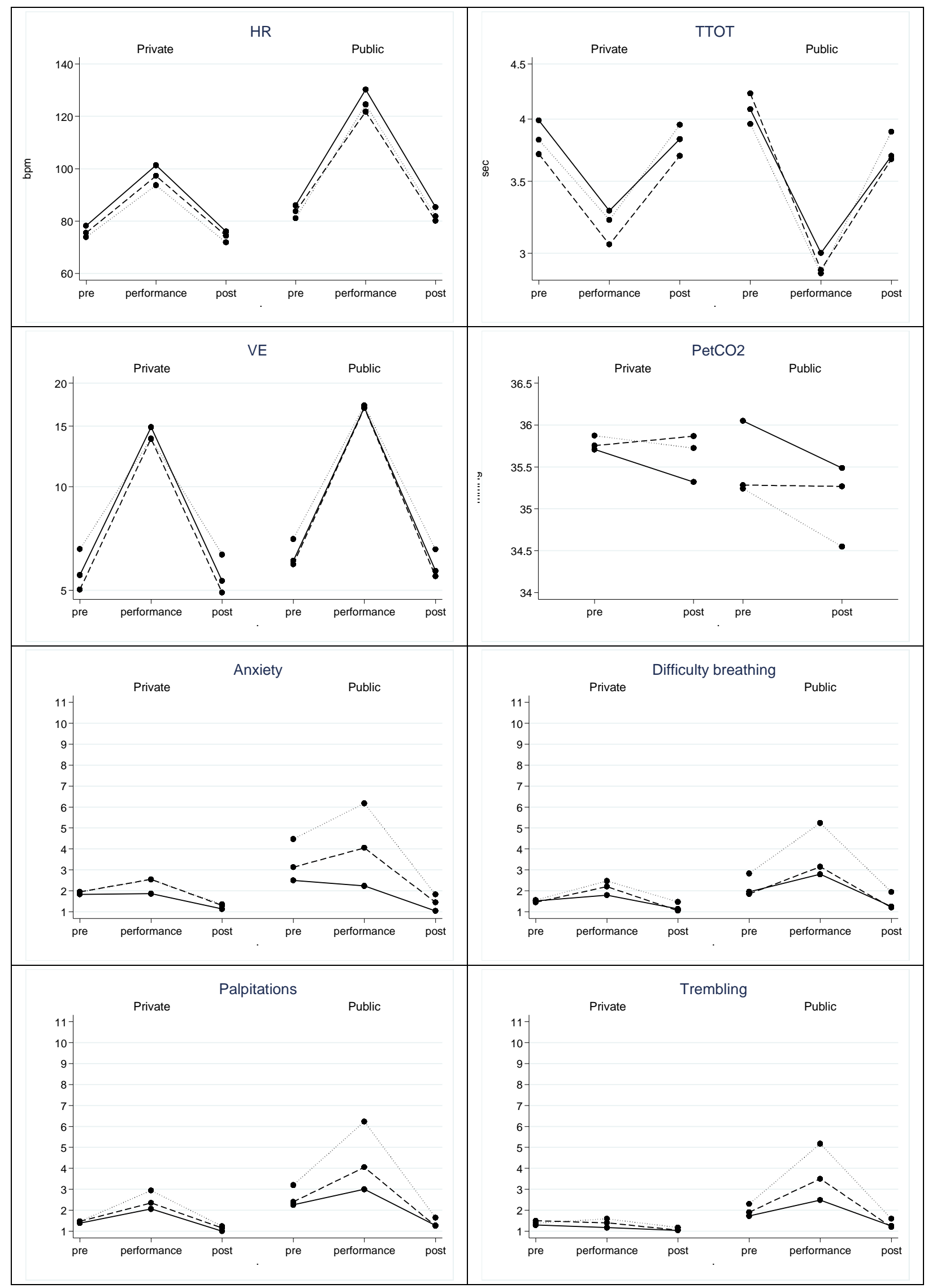


Figure 1: Observed values for physiological and self-report variables over the different assessment periods. To depict the effect of the MPA score on the dependent variables, the figure presents the mean values for the least anxious musicians (STAI-S: 20-44; solid line), the moderately anxious musicians (STAI-S: 45-54; dashed line), and the most anxious musicians (STAI-S: 55-80; dotted line). Y-axes for $\mathrm{T}_{\mathrm{TOT}}$ and $\mathrm{V}_{\mathrm{E}}$ are $\log$ scales. 


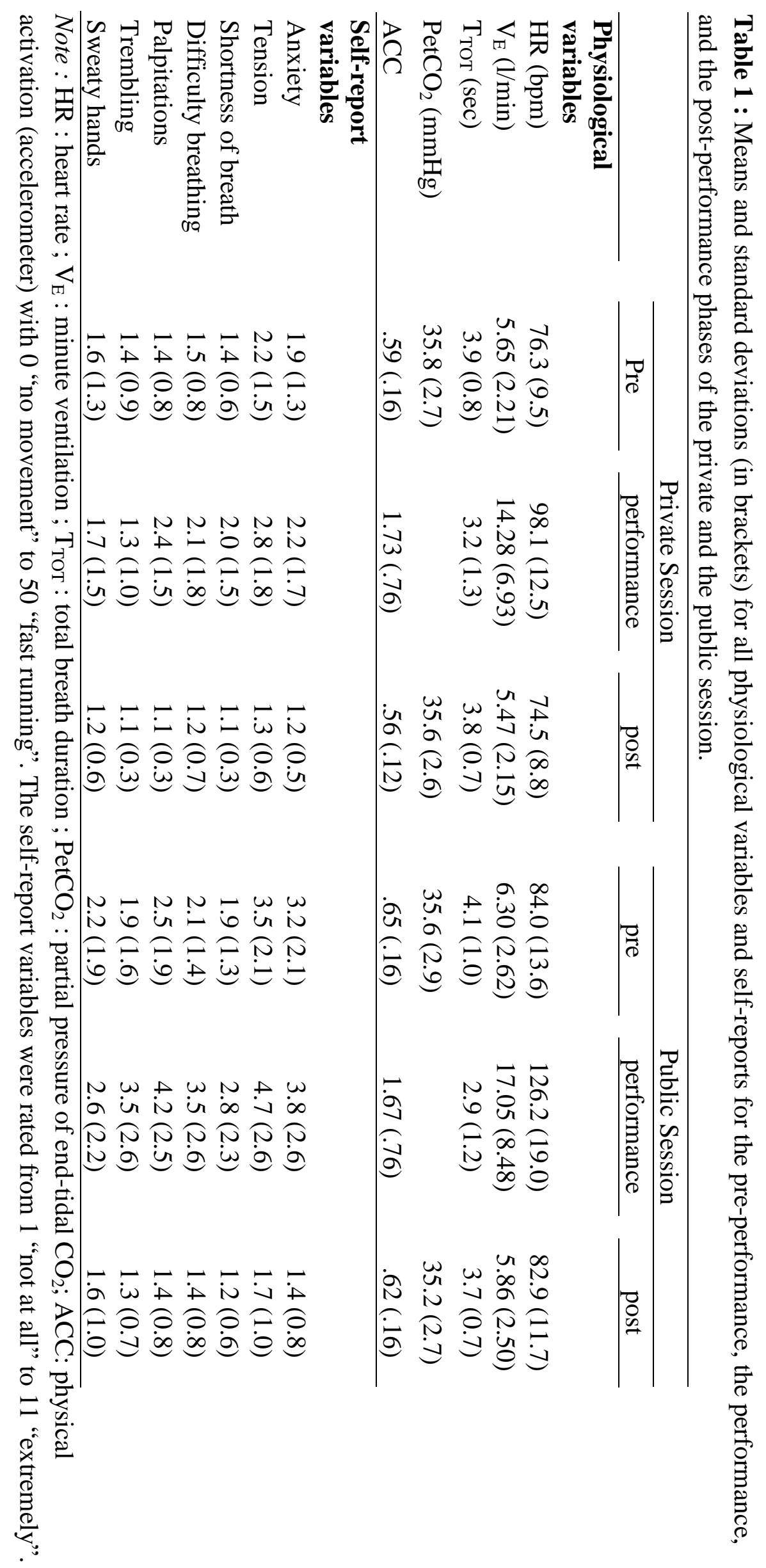




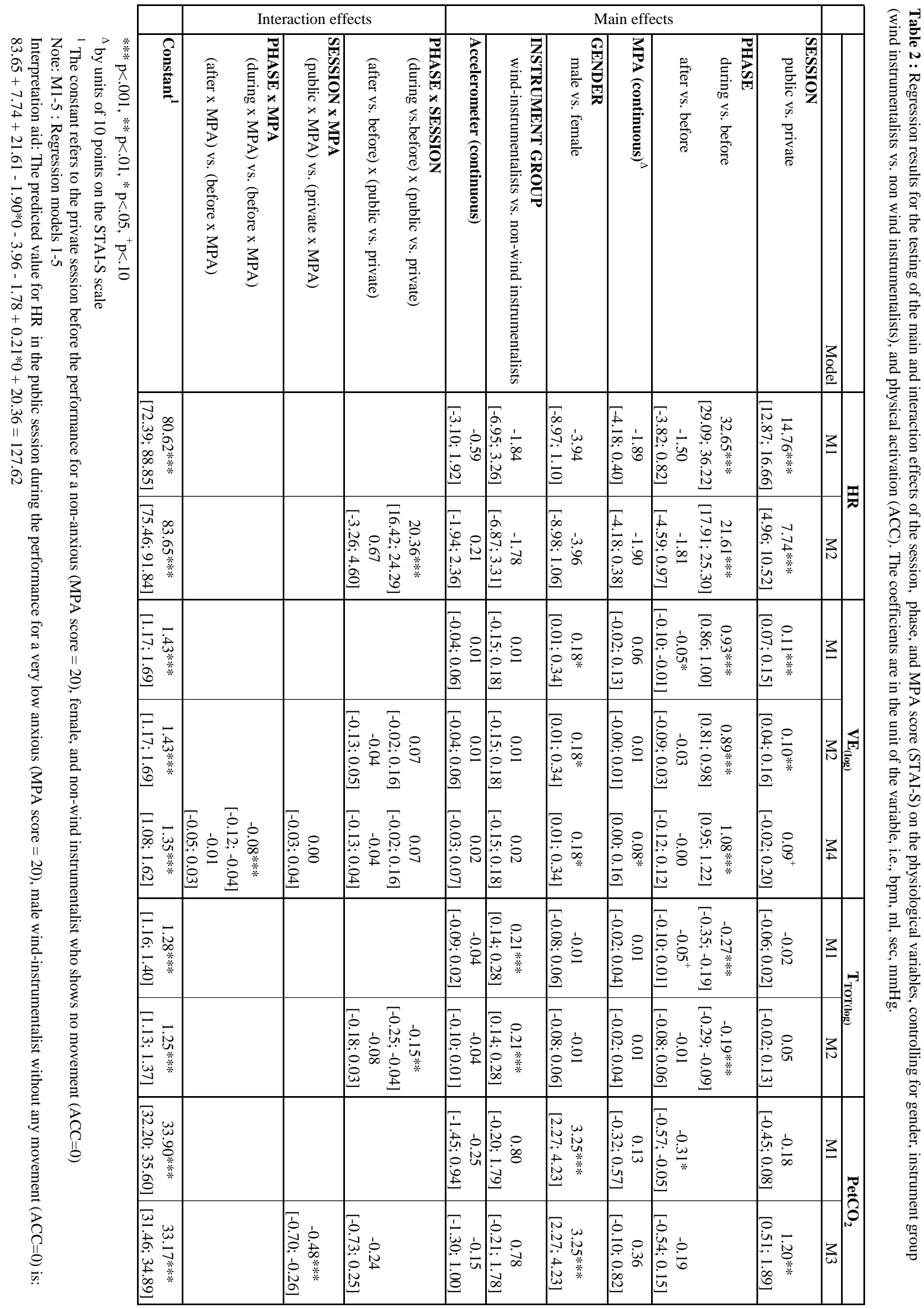




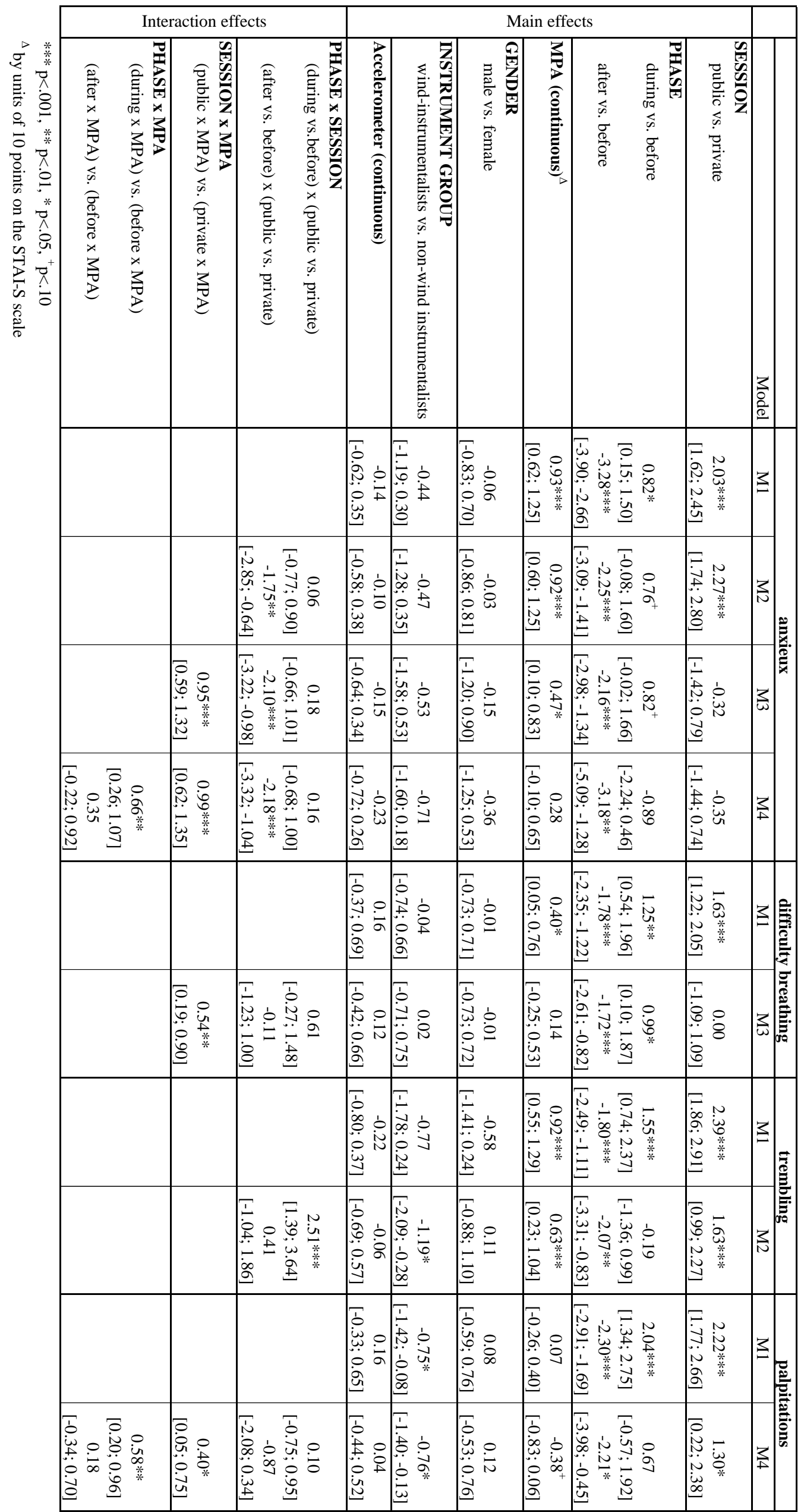

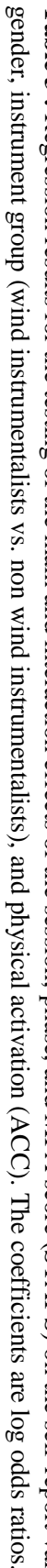

